\title{
INTEGRATION OF HYBRID OUTDOOR AND INDOOR SURVEYING. A CASE STUDY IN SPANISH RENAISSANCE STYLE TOWERS.
}

\author{
J.I. SÁNCHEZ ${ }^{1}$, J.I. San JOSÉ ${ }^{2}$, J.J. FERNÁNDEZ ${ }^{2}$, J. MARTÍNEZ ${ }^{2}$, J. FINAT ${ }^{3}$, \\ ${ }^{1}$ Department of Applied Physics, ETS Arquitectura, 47014 Valladolid \\ ${ }^{2}$ Laboratory Architectural Photogrammetry, ETS Arquitectura, 47014 Valladolid \\ University of Valladolid, Spain, lfa@ega.uva.es \\ ${ }^{3}$ Dept of Algebra and Geometry, ETS Ingeniería Informática, University of Valladolid, 47011 \\ Spain, jfinat@agt.uva.es
}

Keywords: Architectural Surveying, range-based methods, Renaissance towers, conservation interventions.

\begin{abstract}
The fusion of different image- and range-based techniques is acknowledged as the best option for threedimensional surveying of objects displaying a complicated geometry at different scales and/or resolutions. A special case deserving still several challenges involves to towers which represent a compendium of constructive elements and, consequently, a large amount of problems related to conservation or maintenance interventions. In this work, we display an extended photogrametric approach which includes elements information systems in Architecture with a special regard to structural analysis and some aspects of materials analysis. We illustrate our approach with several examples regarding a hybrid surveying of architectural Renaissance towers which have been constructed in several agrarian zones of the kingdom of Castilla (Spain) along 16th and 17th centuries.
\end{abstract}

\section{INTRODUCTION.}

Along the $16^{\text {th }}$ century a large amount of towers were built in the old kingdom of Castilla which combines Gothic and Renaissance styles in an original way. Often, structural indoor elements are constructed following Gothic tradition (mainly for vaults), but walls and outdoor elements are constructed following early Renaissance style. Besides the undeniable beauty of these hybrid solutions, this way of constructing poses a lot of important problems concerning to the behaviour of structural elements. Indeed, traction efforts of Gothic vaults cannot be solved by means of arbotants, and must be absorbed by buttress which are embedded inside the walls of the tower or are discharged along other structural elements of the church which are located along the feet of the church. This architectural solution would explain the peculiar location of the only Renaissance tower with regard to precedent solutions (a double tower, typically) of the Gothic style. From the middle of the 16th century, liturgical needs emanating from the Trento Concilium are in the origin of changes involving internal spatial organization of churches which have been solved with new techniques and styles. Besides the construction of vestries in the head of churches, baptisteries were built in their opposite side. Because of this, very often one can find a direct and open communication between church and the lower part of towers, where the baptismal font is located. The choir acquires a higher relevance than in precedent centuries, by increasing the church size. It is located at feet of temple, and must incorporate organ and singers in charge of giving more solemnity to the new liturgies. Very often, these activities are located inside of towers, and more specifically the first floor of towers. All these new functionalities introduce additional constraints on the design and readaptation of internal spaces, which modify the interplay between spaces and pose challenges involving the behaviour of different structural components. Besides a discussion about the style and smart constructive solutions, this approach poses intrincate problems for restoration or rehabilitation interventions. Indeed, constructive solutions are only partially known and some elements are not physically accessible, such as the space located between the visible vault and the floor. The presence of fissures or cracks along some walls of these towers displays structural elements in visible or hidden elements. In addition, the composition of materials inside the walls supporting compression efforts is sometimes non-homogenous, or some old interventions have been performed by using non-appropriate elements. Reinforcement of structural elements and replacement of components must be carefully planned to avoid a global crash of the whole fabric. Solutions to be performed require a very careful multiresolution surveying and depend in a strong way of the implicit knowledge of experts in architectural restoration. An extensive recent treatment with a large diversity of techniques is included in [1] 

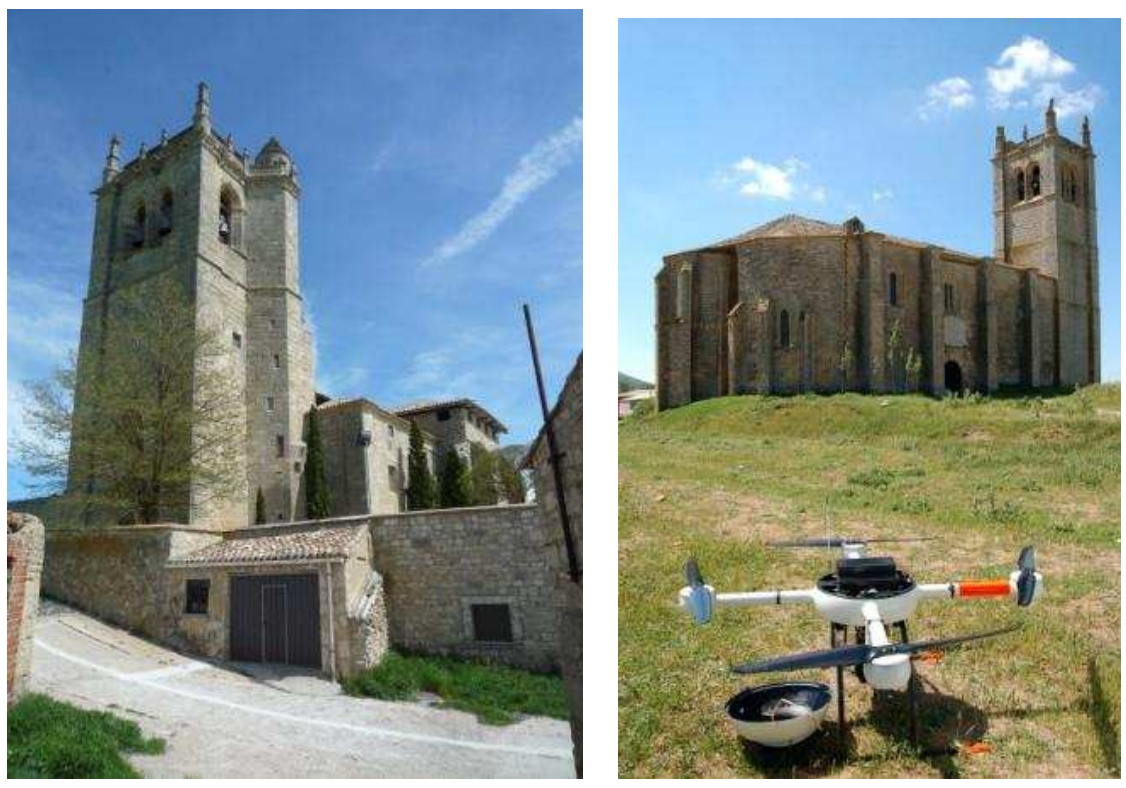

Figure 1: 1) Tower of Santiago's Church, Castrillo de Murcia, Spain. 2) md4-100 capturing aerial images.

Three-dimensional surveying is acknowledged as the most appropriate solution for visualizing interventions: it includes all planar representations which can be obtained from a sectional analysis and provides a support for additional reports. The lack of verticality between structural elements (columns, e.g.) can be obtained by traditional photogrametric methods which provide usual CAD representations as an output. The evaluation of effects related to vertical elements has been emphasized by several authors with applications to religious and civil buildings (see [2] and references therein), with a methodology very similar to ours. The range information provided by laser scan devices provides discrete models with a density which can be selected by user in capture process and sampled in different ways, including superposition of textures obtained from high resolution views, depending on the facilities of the software application. In our case, from the identification of a direction the UVACAD software platform allows to obtain a collection of plane sections with a distance between them selected by user; the superposition of a sequence of parallel "slices". To achieve these goals, we have cut out a collection of horizontal and vertical slices on the 3D model which has been performed with UVACAD (see Fig. 2). These slices can be orthogonally projected on the dominant planes of the involved façades. Projected slices of the point's clouds allow to draw profiles for each level of the tower. The resulting documentation is exported to AutoCad where we represent the geometry and shape of front views for each façade. The availability of metric functionalities on AutoCad allows comparing and evaluating small differences between parallel sections or profiles corresponding to each involved element. The space limitations for optimal localization of devices (laser scans, typically), the overlapping of structural elements (self-occlusive stairs, e.g.) or the existence of hidden components (inside the walls or the slabs, e.g.) in a very reduced space make more difficult the surveying and the interpretation of the tower. For solving these problems, we have developed several software solutions which provide a support for their integration in a global model and provide a support for interpreting it, before assessing the interventions to be performed. These software tools concern to a projection of image-based information on a common model, a semi-automatic recognition of elements (walls and simple vaults) for evaluating structural defects, an integration of non-intrusive techniques in 3D models for materials which can be displayed to several levels of detail, a modular representation of components as support for a future taxonomy and a visualization tool able of integrating information linked to structural components and materials characteristics. The rest of the paper is organized as follows. Section 2 is focused to give a methodological overview able of integrating Documentation, Information and Management Systems as successive stages in regard to conservation and rehabilitation tasks and their application to towers. Section 3 provides some remarks relative to the used non-destructive techniques which are superimposed to the Information System. Section 4 is devoted to the main problems from the structural viewpoint which imposes the most meaningful constraints regarding the intervention agenda. Section 5 illustrates our approach with several examples arising from Renaissance towers in Burgos and Palencia (Spain). Section 6 advances some conclusions and sketches the next steps to be done in future development. 


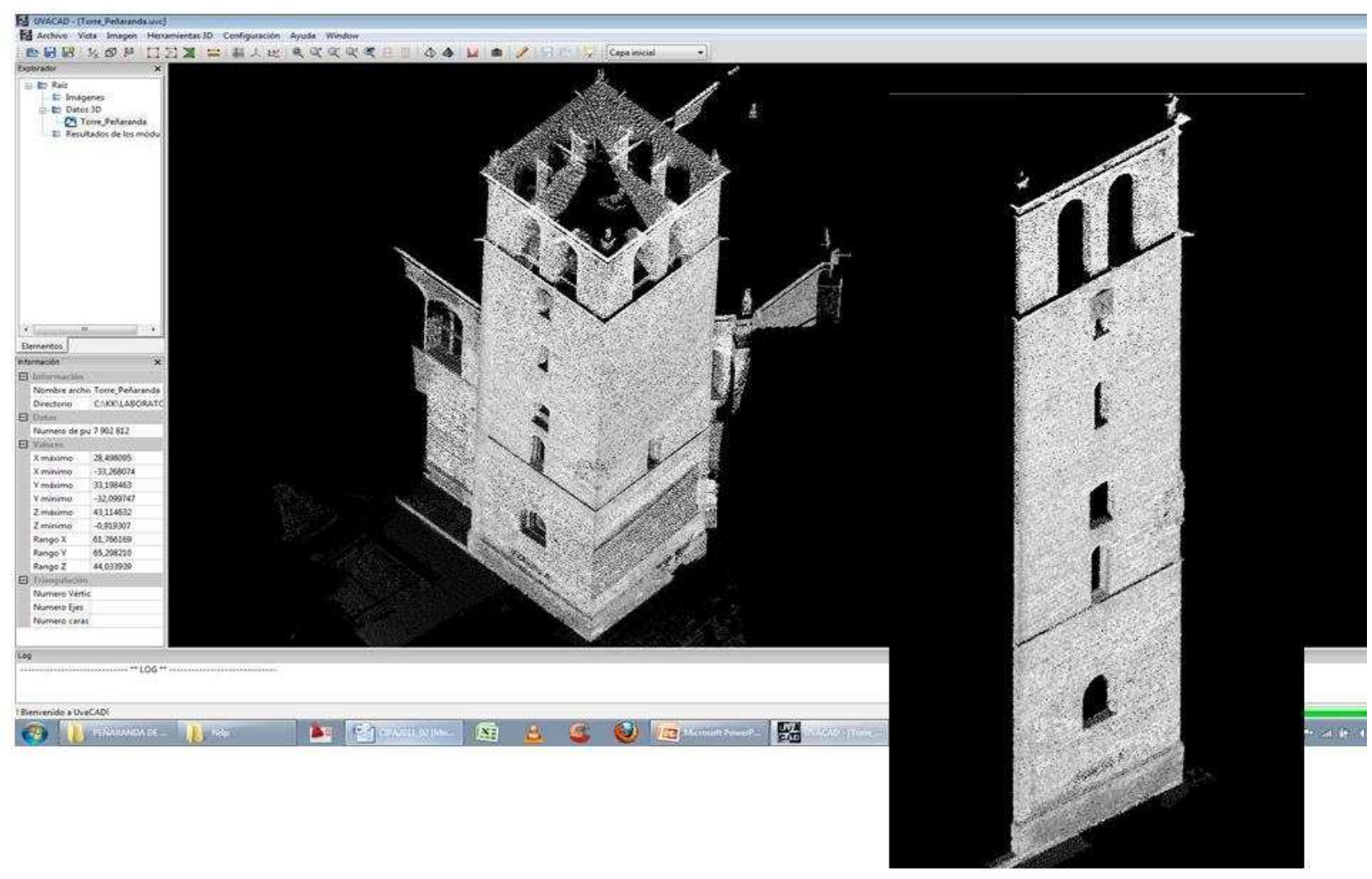

Figure 2: Point cloud processing by UVACAD software.

\section{A LAYERED APPROACH: DIM SYSTEMS}

In layered approaches from Geographic Information Systems (GIS) each document provides the support for different kinds of information linked to provide a support for computing and assessing interventions. The same methodology can be applied to any kind of objects which can be classified within three systems:

1) Documentation Systems for any kind of historic files and recent representation linked to topographic, mapping or volumetric aspects, and their mutual relations in the ambient space which are reference to an accurate geometry. In our case, all data relative to the building is referred to a volumetric representation which allows recovering any kind of information which is managed by simple queries in a $\mathrm{kD}$-tree. The main goal is to provide a support for tracking building temporal evolution, related to the methodology of [4].

2) Information Systems in Architecture focused towards deconstructive process with an emphasis on technicalconstructive elements involving the structure and materials. Its functionalities include semi-automatic or manual insertion of relevant data for each layer referred to raster or vectorial data, basic computations relative to metrics (lengths, areas, volumes) or annotations relative to involved materials in their localizations in a very precise way. The main goal is the development of knowledge of the whole building including structural and materials analysis of the fabric, in their context. There is an increasing number of Information Systems for Cultural Heritage applications, including Archaeological sites (see [5]).

3) Management Systems for constructive process, including formal factors involving the architectural linguistic issues (style, original constructive elements), normative frameworks and choice of the best strategy for intervention. The connection with Information System includes some functionality linked to the representation and management of data which are subject of intervention. In particular, it is necessary to manage a basic statistics relative to performed measurements, a currently manual identification of critical values, software tools for multicriteria analysis and tools for tracking interventions. The main goal is to provide an assistance for agenda planning and tracking conservation or rehabilitation interventions on the building, according to internal constraints (technological aspects) and external 
requirements (arising from the client). It is necessary to develop a good methodology for integrating Documentation, Information and Management Systems in regard to rehabilitation and conservation policies.
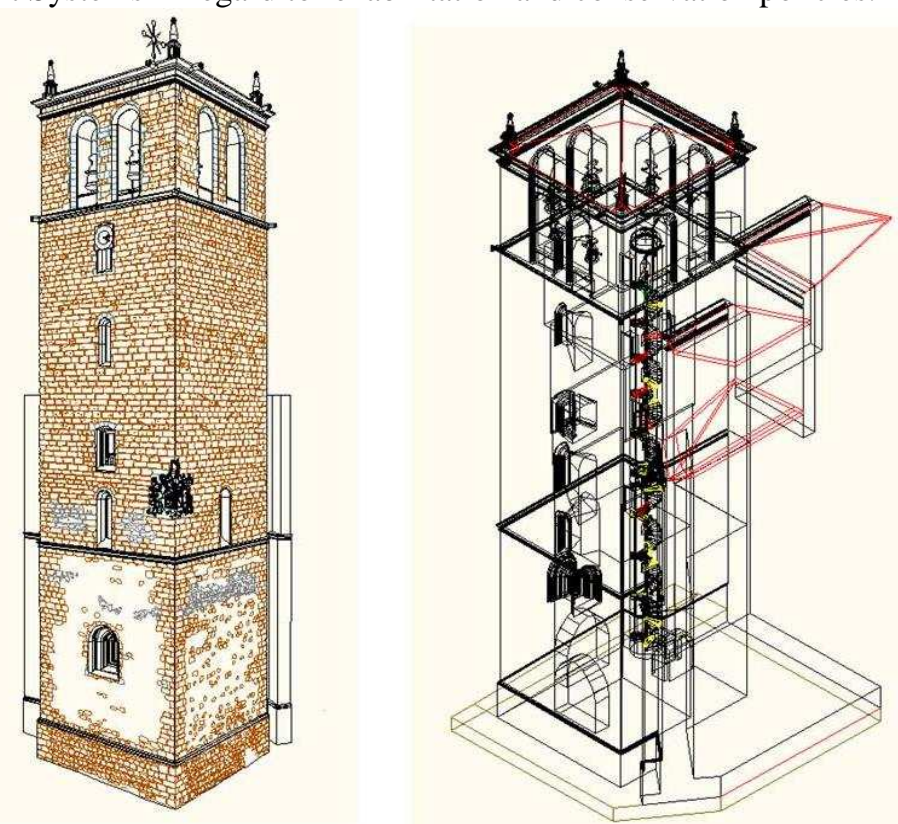

Figure 3: Volume rendering and building elements of St. Ana's tower in Peñaranda de Duero, Spain.

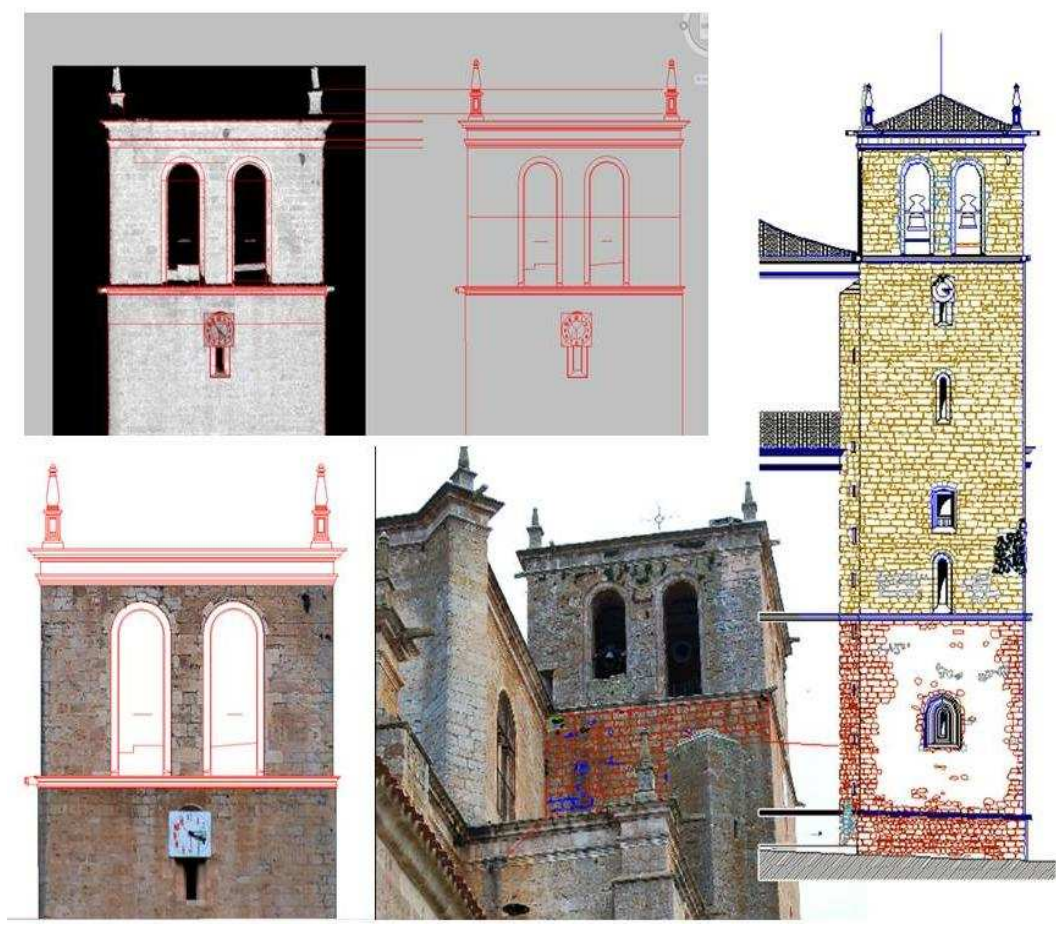

Figure 4: Graphic drafting process from the point cloud model.

A deconstructive or top-down methodology provides the nexus between the above systems. In this work we shall concentrate on those aspects of Information System which are strongly related with structural aspects. As the first step, it is necessary perform a 3D surveying of outdoor and indoor spaces, and match together the resulting models for obtaining the current state of the whole building. Furthermore, it is desirable to refer the structural and material characteristics of the fabrics -including the observed pathologies- to the resulting model, in such way that one can activate analysis, diagnoses and possible interventions by activating different layers involving outdoor and indoor 
representations. Nevertheless the profusion of decorative elements, the exterior surveying is performed by means of a standard combination of image- and range-based modelling, including eventually some information arising from aerial photography. Interior environments display a better accessibility, but on the opposite side, indoor typologies are not homogeneous and they display several architectural characteristics, with different constructive solutions (involving charge walls, vaults, stairs, e.g.) which are combining between them in a complex way.

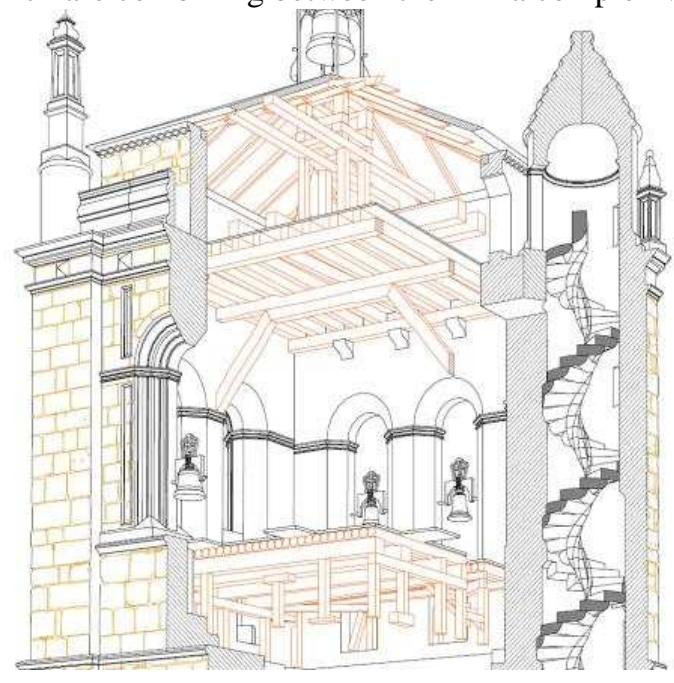

Figure 5: Structures and decorations of a tower building system.

\section{A CONCEPTUAL FRAMEWORK FOR NON-DESTRUCTIVE TECHNIQUES}

A conceptual framework must solve semantic aspects concerning to the intervention project. These issues concern to classification criteria, the identification of the most appropriate hierarchy and the choice of instruments to be applied before executing interventions. They concern to the choice of semi- or non-destructive techniques (SDT or NDT in the successive), and the software tools for their management. SDT are focused towards identifying constructive pathologies an store information from different kinds of waves linked to visual or acoustic information captured with different kinds of (non-contact or contact) devices. Nevertheless the importance of acoustic devices for materials composition and extensometers for evaluating efforts, we shall concentrate our attention in image- and range-based devices. Additionally, this choice is justified in our case by the quasi-homogeneous character of walls supporting compression efforts, and the relatively good state of conservation in the fabrics. Visible or non-visible spectrum from such devices is stored in different formats referred to a common 3D representation of the object. In our hierarchical approach, results arising from the application of NDT are stored by the Management system which frame the information according to the corresponding ontology. Our ontology has several layers, involving metadata and more specific lexicon, thesauri and taxonomies for the knowledge management system (KMS). The $0^{\text {th }}$ layer corresponds to Dublin Core Standards for making easier the interoperability with other software applications. The $1^{\text {st }}$ layer is based on a thesauri for Cultural Heritage which has been developed for solving accessibility issues in the framework of the Singular Strategic Project Patrac, but which extends traditional accessibility issues to more general aspects involving interventions in Cultural Heritage buildings. A description of our KMS can be found in [5]. Software Tools currently in development follows a two-step strategy. 1) Quasi-static WebGIS which includes multi-resolution functionalities such as showed in [6,7]; our additional contribution consists of introducing a Scalable Vector Graphics for the management of geometric and materials entities. This scheme has been applied in the Portics of the Cathedral of Leon. 2) Dynamic WebGIS which is focused on the provision of Web Services including advanced visualization tools for representing, monitoring, tracking, validating or correcting the performed interventions. Some geospatial technologies related with our work have been proposed as standards by the OpenGIS Consortium and they are currently in development for Geomatics (IO/TC 211) or interventions at larger scale.

\section{APPLICATION FOR SURVEYING STRUCTURAL AND MATERIALS PROBLEMS}

Most structural problems can be detected from planimetric information by means of a comparison of sectional representations given by planes which are perpendicular to one of the principal axis of the architectural object. Nevertheless their volumetric effects, main structural problems concern to compression and traction problems holding 
along principal planes. Traditional decompositions of efforts provides a support for identifying efforts in different components trying to validate models and evaluate solutions before executing the most appropriate interventions. Usual rehabilitation solutions are planned and executed following parallel or perpendicular directions to effort direction. This is a natural 3D extension of approaches based in region decomposition which can be distributed according to façade characteristics.
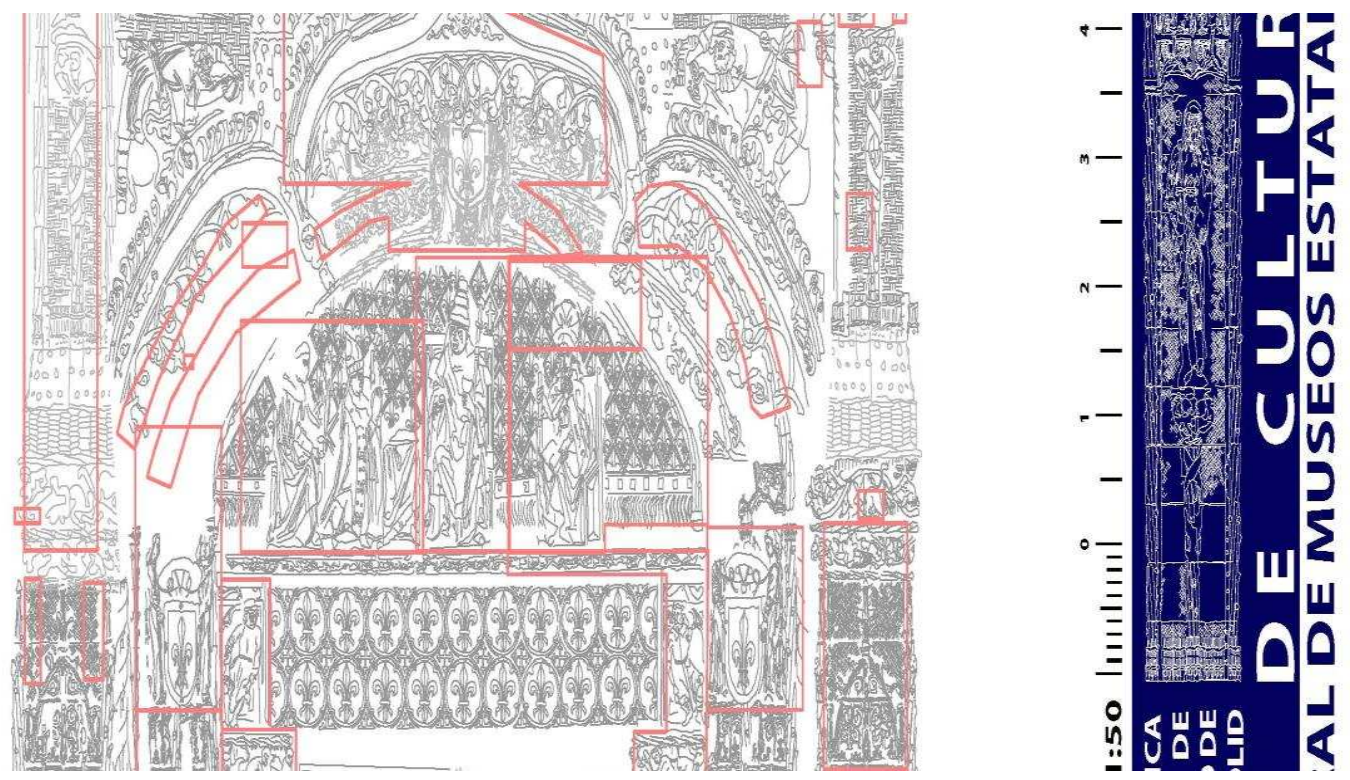

Figure 6: Damage indication and treatment in the facade of San Gregorio, Valladolid, Spain.

However, this is not the only meaningful case because torsion effects cannot be represented in a planar way. Torsion effects are especially meaningful in spiral stairs which are the most common ones inside towers. Often, all steps share a vertical support given by a central column which discharges compression effects against the ground along the vertical; however, the other extreme of each step is coupled to lateral walls and generate an additional effort distributed along contact points of each spirals in a cylinder which must be compensated with a reinforcement of structural elements. Most cases, visual defects (fissures or cracks, e.g.) arise from structural failures relative to uncompensated efforts. The lack of homogeneity of components, biological degradation (deposition of organic residues, e.g.), or damages due to atmospheric conditions are the main responsible. Their accumulation can produce undesirable effects which have to be reviewed in a periodic way. Their tracking is easier with an Information System which has been applied since more than ten years in different monuments. Figure 6 displays a template with different thematic layers for detecting and annotating problems at the façade of San Gregorio (Valladolid, Spain) or the Gothic portics of the Cathedral of Leon (Spain). First approach was manually performed and requires a post-processing work, whereas the second one was annotated in a portable laptop.

\section{SOME MEANINGFUL EXAMPLES}

The analytical process of the buildings showed in this section requires the generation of 3D models from raster data and geometric descriptions specified by plants, front views and cross sections. Digital files are constructed in AutoCAD, where a structural ordering linked to geometric primitives can be performed for all elements appearing in the architectural configuration of towers. An essential graphical resource for drawing is given by sections which allow displaying the articulation between interior spaces of the tower, and the relative disposition between elements and constructive systems. Furthermore, a section-based representation allows explaining the relation between architectural spaces and the articulation between levels and hollows. For achieving an understanding of such complex architectural components it is necessary to generate multiple sections following different orientations and disposals. The deletion of some parts of internal walls and structures makes possible the understanding and organization of the whole fabric. An axonometric perspective allows understanding the relative disposition between parts (which are partially occluded in real models), drawing stairs and identifying their structural role for communicating different floors. Furthermore, this representation supports structural information involving slabs and vaults covering tower spaces, and typical shapes which characterize an architectural style, between others. A related methodology for another kind of materials was developed in [7]. The graphical representation provides is useful not only for interactive visualization but also for 
analytical representation supporting geometric information. Then, it is possible to understand formal and constructive elements involving the space use through the tower organization, and to translate them through the drawing. In this way, drawing becomes an element to improve the knowledge of the building as a whole which includes three aspects related to the complex organization of towers:

- Composite laws which establish the articulation between elements which are part of towers.

- Knowledge of systems / elements which are grouped in the constructive definition of each building.

- Paraments organization by means of the analysis of details, the fabrics composition and the relative disposal and shape of hollows.

In addition, the performed analytical process has allowed to study modifications and alterations along the whole life cycle, thought vestiges and evidences which are currently present in the building. This study makes possible to draft 3D representations which reassemble the description of precedent states, and allow understanding the building evolution through the comparison of vestiges with the current state. Moreover, the photogrametric work performed at field work becomes especially useful for the paraments analysis, not only for its evocation capability between observation and specification of punctual aspects, but because it provides the data support for constructive characteristics of materials. Last ones include specific features for wall materials, and graphical textures which have been used in constructing or remodelling towers.
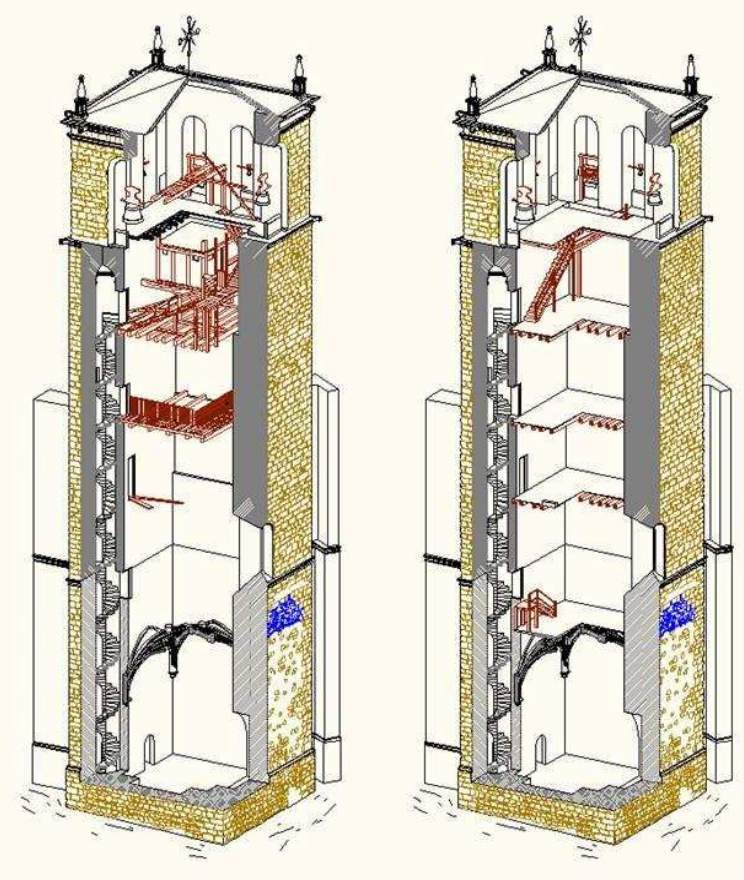

Figure 7: Analysis of current and ideal state of the Santa Ana's tower in Peñaranda de Duero, Spain.

The analysis of local details involving ashlars and rough stones to solve the tower parameters is dealt with three techniques. 1) a direct reading of the coloured point clouds which have been processed for generating vertical or frontal views in the most appropriate resolution. 2) a rectification of views with AsRix, which provides the assembling way of fabrics, as much as their texture and colour constrained due to the lack of coplanarity. 3) a drawing reactivation (Homograft) to translate the formal aspects involving the walls fabrics.

\section{CONCLUSIONS}

Surveying of Renaissance towers poses a difficult challenge due to the diversity of constructive solutions, and the relatively small environments for capturing data. Some of the most important problems concern to hidden parts in documentation phase, and the lack of enough data for a complete structural or materials analysis. It is necessary to work and take decisions under incomplete information, by minimising risks along the intervention. Far from being a 
particular case, the typology of Renaissance towers poses a benchmark for essaying and validating an integrated methodology. The proposed methodology in this paper makes use of homographies for analysing details and pathologies in walls, combining inputs from different sources such as image and range information. This goal also requires continuous feedback between Documentation, Information and Management Systems in a common framework for planning interventions which is the main challenge we are currently addressing.

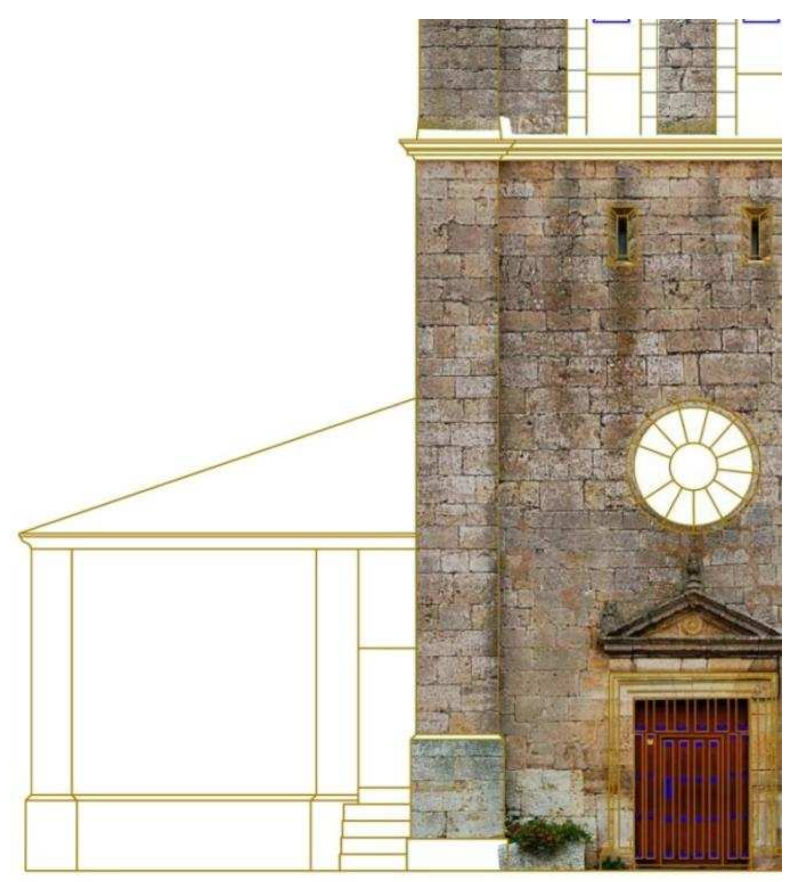

Figure 8: Photo grinding walls in the tower of the Santa Marina's church in Villadiego, Spain.

\section{ACKNOWLEDGEMENTS}

This work is partially supported by the MICINN (Spanish Ministry of Science and Innovation) within the ADISPA project BIA2009-14254-C02-01.

\section{REFERENCES}

[1] Structural Analysis of Historic Constructions (2 vols), 7th International Conference on Structural Analysis of Historic Constructions, SAHC, October 6-8, 2010, Shanghai.

[2] F.Guerra, L.Pilot and P.Vernier: "The facades of gothic buildings in venice: surveys verifying construction theories", CIPA XX Intl Symp., (Torino, 2005).

[3] Drap et al: "Photogrammetry and Archaeological Knowledge: Toward a 3D Information System dedicated to medieval archaeology: a case study of Shawbak Castle in Jordan", 3D AREACH (2007, Switzerland)

[4] S. F. El-Hakim, J.-A. Beraldin, L. Gonzo, E. Whiting, M. Jemtrud, V. Valzano: “A hierarchical 3D Reconstruction approach for Documenting Complex Heritage Sites, XX CIPA Intl Symp,. Torino 2005.

[5] Cadenas. P, García-Tomillo. J., Rodríguez-Cano. G and Finat. J. Software interoperability and friendly interfaces for assessing interventions in cultural heritage domains. $1^{\text {st }}$ International Workshop on Pervasive Web Mapping,

Geoprocessing and Services, WebMGS 2010, ISPRS archive, Vol XXXVIII-4/W13.

[6] E.S. Malinverni, G. Fangi, G. Gagliardini: "Multiresolution 3D Model by Laser data”, ISPRS Vol. XXXIV, Part $5 / \mathrm{W} 12$

[7] Fernández-Martin, J.J., SanJosé, J.I., Martínez, J., Finat, J. Multirresolution Surveying Of Complex Façades: A Comparative Analysis Between Digital Photogrammetry And 3d Laser Scanning, CIPA XX Intl Symp Torino, 2005

[8] A.Anzania, L.Binda, A.Carpinteri, S.Invernizzi, G.Lacidogna: "A multilevel approach for the damage assessment of Historic masonry towers", J. of Cultural Heritage 11 (2010) 459-470 